\title{
Erratum to: Predator interference alters foraging behavior of a generalist predatory arthropod
}

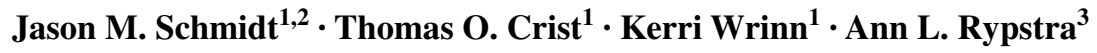

Published online: 14 August 2015

(C) Springer-Verlag Berlin Heidelberg 2015

\section{Erratum to: Oecologia (2014) 175:501-508 \\ DOI 10.1007/s00442-014-2922-x}

Unfortunately, the Electronic Supplementary file was partly omitted in the published article. The complete file is linked with this article.

The online version of the original article can be found under doi:10.1007/s00442-014-2922-x.

Electronic supplementary material The online version of this article (doi:10.1007/s00442-015-3417-0) contains supplementary material, which is available to authorized users.

Jason M. Schmidt

jason.schmidt@uky.edu

1 Department of Zoology, Miami University, Oxford, $\mathrm{OH} 45056$, USA

2 S-225 Agricultural Science Center North, Lexington, KY 40546-0091, USA

3 Department of Zoology, Miami University, Hamilton, OH 45011, USA 